\title{
Determinants of Uterine Rupture and Its Management Outcomes among Mothers Who Gave Birth at Public Hospitals of Tigrai, North Ethiopia: An Unmatched Case Control Study
}

\author{
Meresa Berwo Mengesha $\left(\mathbb{D},{ }^{1}\right.$ Desta Abraha Weldegeorges $\left(\mathbb{D},{ }^{1}\right.$ Yared Hailesilassie $\mathbb{D}{ }^{2}$, \\ Weldu Mammo Werid $\mathbb{D}^{1},{ }^{1}$ Mulu Gebretsadik Weldemariam ${ }^{(D},{ }^{1}$ Fissaha Tekulu Welay $\left(\mathbb{D},{ }^{1}\right.$ \\ Senait Gebreslasie Gebremeskel $\mathbb{D D}^{1}{ }^{1}$ Berhanu Gebresilassie Gebrehiwot $\mathbb{D}^{1}{ }^{1}$ \\ Hagos Degefa Hidru $\left(D,{ }^{3}\right.$ Hirut Teame ${ }^{(D},{ }^{3}$ Haftay Gebremedhin $\left(\mathbb{D},{ }^{3}\right.$ \\ and Natnael Etsay Assefa ${ }^{1}$ \\ ${ }^{1}$ Department of Midwifery, Adigrat University, College of Medicine and Health Sciences, Adigrat, Tigrai, Ethiopia P.O. Box No. 50 \\ ${ }^{2}$ Department of Nursing, Adigrat University College of Medicine and Health Sciences, Adigrat, Tigrai, Ethiopia \\ ${ }^{3}$ Department of Public Health, Adigrat University College of Medicine and Health Sciences, Adigrat, Tigrai, Ethiopia
}

Correspondence should be addressed to Meresa Berwo Mengesha; meresaberu@gmail.com

Received 23 July 2020; Revised 6 October 2020; Accepted 8 October 2020; Published 28 October 2020

Academic Editor: Luca Marozio

Copyright (C) 2020 Meresa Berwo Mengesha et al. This is an open access article distributed under the Creative Commons Attribution License, which permits unrestricted use, distribution, and reproduction in any medium, provided the original work is properly cited.

\begin{abstract}
Introduction. Uterine rupture is a leading cause of maternal death in Ethiopia. Despite strengthening the health care system and providing basic and comprehensive emergency obstetric care closer to the communities, uterine rupture continues to produce devastating maternal and fetal outcomes. Although risk factors of uterine rupture are context specific, there is lack of clarity in our context towards the contributing factors and untoward outcomes of uterine rupture. This study was conducted to identify the risk factors of uterine rupture and its impacts in public hospitals of Tigrai. Objective. This study would identify determinant factors of uterine rupture and its management outcomes among mothers who gave birth in public hospitals in Tigrai region, North Ethiopia. Method. A retrospective hospital-based unmatched case control study design was implemented with 135 cases of women with uterine rupture and 270 controls of women without uterine rupture. Cases were enrolled consecutively from case notes of women who gave birth from 1/9/2015 to 30/6/2019, while charts (case note) of women without uterine rupture found following the cases were selected randomly and enrolled. Bivariate and multivariate logistic regression with 95\% confidence interval was used to identify the determinants of uterine rupture. Result. Mothers referred from remote health institutions (AOR 7.29 (95\% CI: 2.7, 19.68)), mothers who visited once for antenatal care (AOR 2.85 (95\% CI: 1.02, 7.94)), those experiencing obstructed labor (AOR 13.33 (95\% CI: 4.23, 42.05)), and birth weight of a newborn greater than four kilograms (AOR 5.68 (95\% CI: $1.39,23.2)$ ) were significantly associated with uterine rupture. From 135 mothers who develop uterine rupture, 13 (9.6\%) mothers died and $101(74.8 \%)$ fetuses were stillborn. Obstetrical complications like abdominal hysterectomy in 75 (55.6\%) of mothers and excessive blood loss in $84(57.8 \%)$ were additional untoward outcomes of uterine rupture. Conclusion. Referrals from remote health institutions, once-visited antenatal care, obstructed labor, and birth weight of newborns greater than four kilograms were significant determinants of uterine rupture. Maternal death, stillbirth, hysterectomy, and hemorrhage were adverse outcomes. The findings of this study suggest early identification of factors that expose to uterine rupture during antenatal care, labor, and delivery must be attended to and further prospective studies are needed to explore predictors of untoward outcomes. Knowing the determinants of uterine rupture helps prevent the occurrence of a problem in pregnant women, which reduces maternal morbidity and mortality, and would have a tremendous help in identifying the best optional strategies in our current practices. This assertion was added to the abstract concluding session.
\end{abstract}




\section{Introduction}

Uterine rupture is a disruption of the uterine wall during pregnancy or childbirth. Usually, destruction to the uterus is not correctable and the outcome is often a hysterectomy [1]. Uterine rupture is a devastating obstetric condition that put the life of the mother and the baby at risk [2]. Its magnitude is greater in Asia and Africa than in highincome countries [3]. The incidence of uterine rupture in Africa ranges from $0.5 \%$ to $9.5 \%$ of births [4-7].

In Ethiopia, the prevalence of uterine rupture ranges from $1.244 \%$ to $9.5 \%[4,7,8]$. Although the magnitude is relatively low, it accounts for $18.8 \%$ to $36 \%$ of maternal mortality [9] and more than $35 \%$ of registered maternal deaths were due to uterine rupture [4].

Mothers experiencing uterine rupture outcomes range from $3 \%$ to $12.3 \%$ vesicovaginal fistulas, $6.1 \%$ rectovaginal fistulas, and $16 \%$ bladder ruptures; of them were complication of management of ruptured uterus. Direct complication of ruptured uterus includes $59.8 \%$ to $88.8 \%$ which incur severe blood loss; and $14 \%$ to $51.8 \%$ undergo total abdominal hysterectomy. The magnitude of fetal mortality is very high with $1.7 \%$ to $7 \%$ of babies surviving after uterine rupture; $93 \%$ to $98.3 \%$ of them were stillbirths $[4,5,7]$. Though determinant factors for uterine rupture differ across localities due to differences in sociodemographic status, readiness and ease of access to skilled birth attendants, and health system efficacy, previous studies have found that labor induction, grand multiparity, lack of ANC follow-up, history of previous caesarian section $(\mathrm{C} / \mathrm{S})$, prolonged labor, obstructed labor, lack of partograph utilization, and instrumental delivery were significantly associated with uterine rupture [2, 5, 8, 10-13].

Despite strengthening the health care system and provision of basic and comprehensive emergency obstetric care, Ethiopian women continue to face devastating maternal and fetal outcomes, particularly in the study area [14]. This study is aimed at addressing determinant factors of uterine rupture and its adverse maternal and fetal management outcomes in public hospitals of Tigrai. Knowing the risk factors of uterine rupture will potentially assist women, providers, and health systems to take actions on each factor to decrease maternal as well as perinatal morbidity and mortality related to uterine rupture.

\section{Methods and Materials}

2.1. Study Design and Setting. A retrospective hospital-based unmatched case control study design was implemented at public hospitals in Tigrai region, from cards (case notes) of mothers who gave birth from $1 / 9 / 2015$ to $30 / 6 / 2019$. Cards of mothers, who gave birth from $1 / 9 / 2015$ to $30 / 6 / 2019$ in selected public hospitals of Tigrai, were retrieved. We have used an unmatched case control study for frequency and ensured that cases and controls are not identical; however, they are comparable and share the same geographical and social backgrounds. In addition, we have tried to avoid seasonal impact. For example, during rainy seasons, women in rural areas do not come to seek obstetric care at a higher facility due to the unavailability of transportation.

2.2. Selection of Cases. Uterine rupture was defined as tearing of the uterine wall either partially or completely during pregnancy and labor, diagnosed clinically and later confirmed at laparotomy by the attending physician. The cases were obtained from the labor and delivery ward, operating theatre registers, and from the patients' case files retrospectively. Chart number of women diagnosed with uterine rupture who met the criteria was enrolled consecutively.

2.3. Selection of Controls. Controls were women who had spontaneous vaginal delivery or who delivered by caesarean section without uterine rupture as a complication. Charts (case notes) of women without uterine rupture (control) found after the cases (since cases and controls should be comparable regardless of the presence of the disease of interest, we enrolled controls who were admitted following the cases to avoid seasonal impact on transportation from rural areas and other parameters) were selected randomly and enrolled.

2.4. Inclusion Criteria. Cases are all mothers diagnosed with uterine rupture during pregnancy and labor and delivery in selected public hospitals of Tigrai.

Controls are all mothers who gave birth without experiencing uterine rupture in selected public hospitals of Tigrai.

2.5. Exclusion Criteria. If the mother's card (case note) missed dependent and other significant variables under study, then it will be excluded from the study; missed and tear cards were excluded.

2.6. Sample Size Determination. Sample size was calculated using Epi-info Version 7 based on the following assumptions: $95 \%$ level of confidence, $80 \%$ power, taking two to one ratio of controls to case $(2: 1)$. The proportion of control with educational level of primary school is $67 \%$ and the proportion of case with educational level of primary school is $80.63 \%$, with the odds ratio of primary school educated women as 2.05 times more likely to develop uterine rupture [13]. The final sample size was 135 cases and 270 controls. There were 14 incomplete cards (missing essential variables and discarded (tear cards)), and 6 case notes (patient cards) were lost. We have used 5\% contingency for the incomplete and missed patient's cards, while our final complete records for both cases and controls were 405.

2.7. Sampling Procedure. This study was conducted in selected public hospitals in Tigrai. There are 14 general hospitals and two referral hospitals in Tigrai. One referral and four general hospitals were selected randomly from all general and referral hospitals found in Tigrai region. Ayder Referral Hospital, Lemlem Karl General Hospital, Adigrat General Hospital, Adwa General Hospital, and Suhul General Hospital were selected. After calculating the previous five years' admission of mothers in obstetric ward and knowing the total case load in each selected hospital, the sample size 


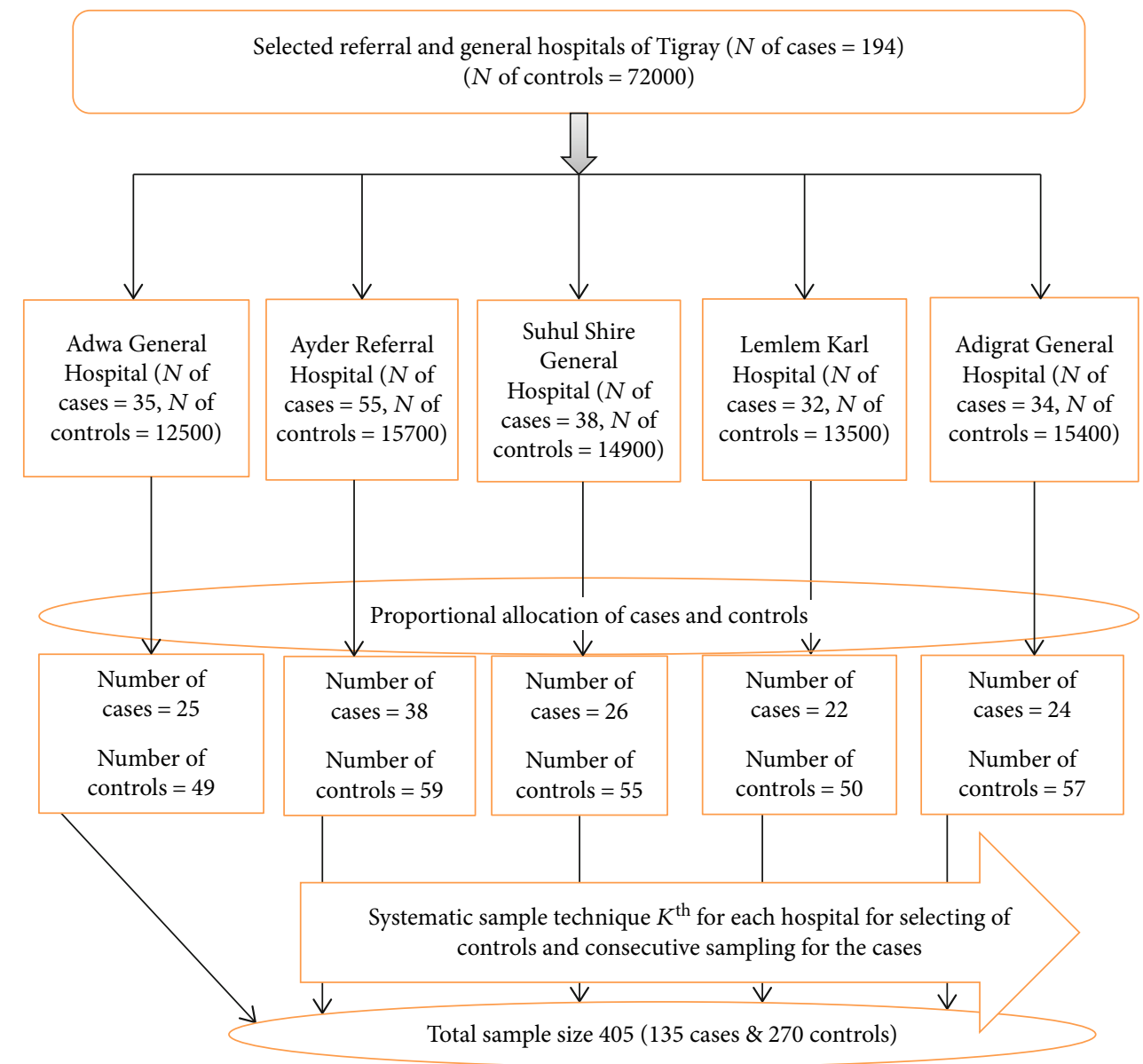

FIGURE 1: Schematic presentation of sampling technique to identify determinants of uterine rupture and management outcomes among mothers who give birth in public hospitals of Tigray, 2018/2019.

was allocated to the hospitals proportionally. In the five years' survey, there were 72000 deliveries without uterine rupture (control) and 194 cases in Adwa General Hospital $(N$ of cases $=35, N$ of controls $=12500)$, Ayder Referral Hospital $(N$ of cases $=55, N$ of controls $=15700)$, Suhul Shire General Hospital ( $N$ of cases $=38, N$ of controls $=14900$ ), Lemlem Karl Hospital ( $N$ of cases $=32, \quad N$ of controls $=$ 13500), and Adigrat General Hospital ( $N$ of cases $=34, N$ of controls $=15400)$. Charts (case note) of women diagnosed with uterine rupture who met the criteria were enrolled consecutively, while charts (case note) of women without uterine rupture (control) found following the cases were selected randomly and enrolled. Given that uterine rupture is rare, we have enrolled charts of women who have met the inclusion criteria until the total sample size was attained (Figure 1).

2.8. Study Variables. The uterine rupture was a dependent variable. Sociodemographic factors claimed in the literatures to determine uterine rupture were maternal age, occupation, referral status, residence, and pregnancy and labor and delivery-related factors including labor induction, grand multiparity, lack of ANC follow-up, history of previous caesarian section $(\mathrm{C} / \mathrm{S})$, prolonged labor, obstructed labor, lack of partograph utilization, and instrumental delivery.
2.9. Data Collection Procedure. Data were collected using a structured checklist adapted from the literature, selecting data from delivery registers, operating theatre registers, and patients' case files, which include sociodemographic variables, pregnancy condition variables, labor and delivery variables, and maternal and fetal management outcomes $[2,4,5,13,15]$. Five data collectors with a Bachelor of Science in Midwifery degree were recruited. Wording and consistency of the checklist were corrected after a pretest was done.

2.10. Data Analysis. The data were entered into Epi data Version 3.5.1 and exported to the Statistical Package for the Social Sciences (SPSS) Version 20 software for further analysis. Descriptive statistics were presented. The odds ratio was with their 95\% confidence interval; two-tailed $P$ value was computed to declare the level of significance. Bivariate and multivariate logistic regressions with $95 \%$ confidence interval were used to identify determinant factors of uterine rupture. Variables with a $P$ value $<0.2$ at the bivariate logistic regression were entered to multivariable logistic regression to identify the independent predictors of uterine rupture, to control the confounding variables, and to produce adjusted odds ratio with their corresponding confidence limits. Before performing the multivariable logistic regression, we tested the 
TABLE 1: Sociodemographic characteristics of cases and controls who gave birth at public hospitals of Tigrai, North Ethiopia.

\begin{tabular}{|c|c|c|c|c|}
\hline Variables & Category & Cases & Controls & Total \\
\hline \multirow{3}{*}{ Age } & $\leq 19$ & $6(4.4)$ & $17(6.3)$ & $23(5.7)$ \\
\hline & $20-34$ & $95(70.4)$ & $211(78.1)$ & $306(75.5)$ \\
\hline & $\geq 35$ & $34(25.2)$ & $42(15.6)$ & $76(18.8)$ \\
\hline \multirow{2}{*}{ Ethnicity } & Tigray & $130(96.3)$ & $267(98.9)$ & $397(98)$ \\
\hline & Afar & $5(3.7)$ & $3(1.1)$ & $8(2)$ \\
\hline \multirow{5}{*}{ Occupation } & Government employee & $9(6.7)$ & $22(8.1)$ & $31(7.7)$ \\
\hline & Housewife & $80(59.3)$ & $138(51.1)$ & $218(53.8)$ \\
\hline & Merchant & $18(13.3)$ & $67(24.8)$ & $85(21)$ \\
\hline & Private employee & $16(11.9)$ & $23(8.5)$ & $39(9.6)$ \\
\hline & Student & $12(8.9)$ & $20(7.4)$ & $32(7.9)$ \\
\hline \multirow{3}{*}{ Religion } & Orthodox Tewahedo & $109(80.7)$ & $249(92.2)$ & $358(88.4)$ \\
\hline & Muslim & $15(11.1)$ & $10(3.7)$ & $25(6.2)$ \\
\hline & Others* & $11(8.1)$ & $11(4.1)$ & $22(5.4)$ \\
\hline Referral status & Yes & $108(80)$ & $67(24.8)$ & $175(43.2)$ \\
\hline
\end{tabular}

presence of multicollinearity between independent variables and no multicollinearity was detected. Then, finally, statistical significance was declared if $P$ value $<0.05$. The goodness of fit of the model was checked by the Hosmer-Lemeshow test. Finally, health facility, number of antenatal visits, experience of obstructed labor, and birth weight of newborn were found to be statistically associated with uterine rupture.

\section{Results}

There were 72000 live births in the study area with 194 cases of uterine rupture in five years' data extraction from case notes of mothers. Given that, the incidence of uterine rupture was 194 in 72000 live births (26.9 in 10000 live births) in the study area.

3.1. Sociodemographic-Related Factors. Four hundred and five mother's cards (case notes) were reviewed based on the sampling of 135 cases and 270 controls. The median age of the women in cases and controls was $30(\mathrm{IQR}=9)$ and 26 $(\mathrm{IQR}=8)$, respectively. One hundred and thirty $(96.3 \%)$ of the cases and 267 (98.9\%) of the controls have Tigrai ethnicity, eighty (59.3\%) of the cases and $138(51.1 \%)$ of the controls were housewives, and $109(80.7 \%)$ of the cases and $249(92.2 \%)$ of the controls were Orthodox Tewahedo believers. One hundred and eight (80\%) and 67 (24.8\%) of the mothers were referred from remote health facilities aligned with cases and controls, respectively (Table 1).

3.2. Obstetric-Related Factors. Forty (29.6\%) of the cases and 35 (13\%) of the controls were grand multiparous ( $\geq 5$ births). The proportion of mothers who did not engage in antenatal care in the cases and controls was 22 (16.3\%) and 13 (4.8\%), respectively. For those who visited antenatal care, $49(43.8 \%)$ of the cases and $170(64.45 \%)$ of the controls had four or more visits. The proportion of women who had previous caesarean delivery in the cases and controls was 26 (19.3\%) and 7 (2.6\%), respectively, while 16 (11.9\%) of the cases and $2(0.7 \%)$ of the controls, who had previous caesarean delivery, had interpregnancy intervals of less than twelve months. Among cases, it was found that 15 (11.1\%) of prehemoglobin maternal case group levels were below $7 \mathrm{~g}$ per $\mathrm{dl}$ while $19(7 \%)$ in the control group were anemic (Table 2).

3.3. Labor-and Delivery-Related Factors. For 127 (94.1\%) of the cases and 269 (99.6\%) of the controls, delivery was at one of the hospitals. Twenty-one $(15.6 \%)$ of the cases and $14(5.2 \%)$ of the controls began their labor spontaneously. In $118(87.4 \%)$ of the cases and $61(22.6 \%)$ of the controls, labor was not followed by partograph. Sixteen $(11.9 \%)$ of the cases and $1(0.4 \%)$ of the controls had more than eighteen hours of labor. The proportion of mothers who experience obstructed labor among the case group was 80 (59.3\%) and $28(10.4 \%)$ in the control group. Five $(3.7 \%)$ of the cases and $12(4.4 \%)$ of the controls were instrument deliveries. Among cases, it was found that 29 (21.5\%) of newborn birth weights were four kilograms as opposed to $18(6.7 \%)$ in the control group (Table 3).

3.4. Factors Associated with Uterine Rupture (Bivariate and Multivariate Analyses). In bivariate logistic regression, 20 variables showed association with uterine rupture at $P$ value of $<0.2$. In multivariate logistic regression, four variables were significantly associated with uterine rupture at $P$ value $<0.05$.

The mothers referred from remote health institutions were 7.29 times more likely to develop uterine rupture compared to those who did not have referrals (AOR 7.29; 95\% CI: $2.7,19.68)$. Mothers who had only one prenatal care visit were 2.85 times more likely to develop uterine rupture compared to those who had four visits or more antenatal care visits with AOR 2.85 (95\% CI: 1.02, 7.94). The odds of developing uterine rupture for women experiencing obstructed 
TABLE 2: Obstetric conditions of cases and controls who gave birth at public hospitals of Tigray, North Ethiopia.

\begin{tabular}{|c|c|c|c|c|c|}
\hline Variables & Category & Cases $N=135(\%)$ & Controls $N=270(\%)$ & Total $N=405(\%)$ & COR $(95 \% \mathrm{CI})$ \\
\hline \multirow{2}{*}{ Parity } & $1-4$ & $95(70.4)$ & $235(87)$ & $330(81.5)$ & 1 \\
\hline & $\geq 5$ & $40(29.6)$ & $35(13)$ & $75(18.5)$ & $2.83(1.69,4.72)$ \\
\hline \multirow{2}{*}{ Antenatal follow-up } & No & $22(16.3)$ & $13(4.8)$ & $35(8.6)$ & $3.85(1.87,7.91)$ \\
\hline & Yes & $113(83.7)$ & $257(95.2)$ & $370(91.4)$ & 1 \\
\hline \multirow{3}{*}{ Number of antenatal visits } & 1 & $12(10.7)$ & $22(8.3)$ & $34(9)$ & $1.89(0.88,4.09)$ \\
\hline & $2-3$ & $51(45.5)$ & $72(27.3)$ & $123(32.7)$ & $2.46(1.52,3.97)$ \\
\hline & $\geq 4$ & $49(43.8)$ & $170(64.4)$ & $219(58.2)$ & 1 \\
\hline \multirow{3}{*}{ Gestational age in weeks } & $28-37$ & $44(32.6)$ & $60(22.2)$ & $104(25.7)$ & 1 \\
\hline & $37-42$ & $82(60.7)$ & $198(73.3)$ & $280(69.1)$ & $0.56(0.35,0.9)$ \\
\hline & $\geq 42$ & $9(6.7)$ & $12(4.4)$ & $21(5.2)$ & $1.02(0.39,2.64)$ \\
\hline \multirow{2}{*}{$\begin{array}{l}\text { Number of pregnancy } \\
\text { when ruptured }\end{array}$} & Singleton & $135(100)$ & $263(97.4)$ & $398(98.3)$ & 1 \\
\hline & Multiple & 0 & $7(2.6)$ & $7(1.7)$ & NA \\
\hline Previous caesarean delivery & Yes & $26(19.3)$ & $7(2.6)$ & $33(8.1)$ & $8.96(3.78,21.26)$ \\
\hline \multirow{2}{*}{$\begin{array}{l}\text { Interpregnancy interval } \\
\text { after CS }\end{array}$} & Less than 12 months & $16(11.9)$ & $2(0.7)$ & $18(4.4)$ & $4.83(1.61,14.45)$ \\
\hline & Above 12 months & $10(7.4)$ & $5(1.9)$ & $15(3.7)$ & 1 \\
\hline \multirow[t]{2}{*}{ Chorioamnionitis } & Yes & $4(3)$ & $1(0.4)$ & $5(1.2)$ & $8.21(0.91,74.22)$ \\
\hline & $\leq 7$ & $15(11.1)$ & $19(7)$ & $34(8.4)$ & $2.68(1.29,5.56)$ \\
\hline \multirow[t]{2}{*}{ Prehemoglobin level } & $7-11$ & $54(40)$ & $27(10)$ & $81(20)$ & $6.79(3.96,11.62)$ \\
\hline & $\geq 12$ & $66(48.9)$ & $224(83)$ & $290(71.6)$ & 1 \\
\hline
\end{tabular}

$\mathrm{NA}=$ not applicable because of few in numbers. Prehemoglobin level: the level of hemoglobin before uterine rupture.

TABLE 3: Labor and delivery distributions of cases and controls who gave birth at public hospitals of Tigrai, North Ethiopia.

\begin{tabular}{|c|c|c|c|c|c|}
\hline Variable & Category & Cases $N=135$ & Controls $N=270$ & Total $N=405$ & COR $(95 \%$ CI $)$ \\
\hline \multirow{2}{*}{ Place of delivery } & Health center & $8(5.9)$ & $1(0.4)$ & $9(2.2)$ & $16.94(2.09,130.09)$ \\
\hline & Hospital & $127(94.1)$ & $269(99.6)$ & $396(97.8)$ & 1 \\
\hline \multirow[t]{2}{*}{ Partograph use } & No & $118(87.4)$ & $61(22.6)$ & $179(44.2)$ & $23.78(13.23,42.60)$ \\
\hline & Yes & $17(12.6)$ & $209(77.4)$ & $226(55.6)$ & 1 \\
\hline Duration of labor & More than $18 \mathrm{~h}$ & $16(11.9)$ & $1(0.4)$ & $17(4.2)$ & $10.19(1.32,78.54)$ \\
\hline Obstructed labor & Yes & $80(59.3)$ & $28(10.4)$ & $108(26.7)$ & $12.57(7.47,21.15)$ \\
\hline Malpresentations & Yes & $18(13.3)$ & $17(6.3)$ & $35(8.6)$ & $0.44(0.21,0.88)$ \\
\hline \multirow{2}{*}{ Instrumental delivery } & No & $130(96.3)$ & $258(95.6)$ & $388(95.8)$ & 1 \\
\hline & Yes & $5(3.7)$ & $12(4.4)$ & $17(4.2)$ & $1.51(0.48,4.77)$ \\
\hline \multirow{2}{*}{ Labor started spontaneously } & No & $21(15.6)$ & $14(5.2)$ & $35(8.6)$ & $3.37(1.65,6.86)$ \\
\hline & Yes & $114(84.4)$ & $256(94.8)$ & $370(91.4)$ & 1 \\
\hline \multirow{2}{*}{ Trial of labor after CS } & No & $122(90.4)$ & $267(98.9)$ & $389(96)$ & 1 \\
\hline & Yes & $13(9.6)$ & $3(1.1)$ & $13(9.6)$ & $9.48(2.65,33.89)$ \\
\hline \multirow{2}{*}{ Congenital anomaly of baby } & No & $126(93.3)$ & $267(98.9)$ & $393(97)$ & 1 \\
\hline & Yes & $9(6.7)$ & $3(1.1)$ & $12(3)$ & $6.36(1.69,23.89)$ \\
\hline \multirow{2}{*}{ Birth weight } & $<4$ & $106(78.5)$ & $252(93.3)$ & $358(88.4)$ & 1 \\
\hline & $\geq 4$ & $29(21.5)$ & $18(6.7)$ & 47 (11.6) & $3.83(2.04,7.19)$ \\
\hline
\end{tabular}

Obstructed labor: attending physician diagnosed using American College of Obstetricians and Gynecologists (ACOG) obstructed labor as arrest of labor during the first and second stages of labor despite adequate uterine contraction because of mechanical obstruction manifested by signs of severe obstruction: caput and moulding formation, Bandl's ring, and edematous vulva.

labor were 13.33 times higher compared to those who had no experience with obstructed labor (AOR 13.33; 95\% CI: 4.23, 42.05). Those whose birth weight of newborns was four and above kilograms were 5.68 times more likely to have uterine rupture than those who had newborns less than four kilograms (AOR 5.68; 95\% CI: 1.39, 23.2) (Table 4).
3.5. Maternal and Fetal Outcomes of Uterine Rupture. Out of 135 mothers who develop uterine rupture, intraoperative findings found that 75 (55.5\%) had a complete uterine rupture. With respect to the rupture location, 47 (34.8\%) were anterior, 53 (39.25\%) posterior, and 35 (25.92\%) lateral. Total abdominal hysterectomy was done in $47(34.8 \%)$ of 
TABLE 4: Bivariate and multivariable logistic regression analysis result of significant variables $(P$ value $<0.05)$ at public hospitals in Tigrai, North Ethiopia.

\begin{tabular}{|c|c|c|c|c|}
\hline Variables & Category & Cases & Controls & AOR $(95 \% \mathrm{CI})$ \\
\hline \multirow{3}{*}{ Age of mother } & $\leq 19$ & $6(4.4)$ & $17(6.3)$ & 1 \\
\hline & $20-34$ & $95(70.4)$ & $211(78.1)$ & $1.37(0.07,44.8)$ \\
\hline & $\geq 35$ & $34(25.2)$ & $42(15.6)$ & $3.09(0.09,104)$ \\
\hline \multirow{2}{*}{ Ethnicity } & Tigrai & $130(96.3)$ & $267(98.9)$ & 1 \\
\hline & Afar & $5(3.7)$ & $3(1.1)$ & $0.9(0.61,13.29)$ \\
\hline \multirow{2}{*}{ Referral status } & No & $27(20)$ & $203(70.4)$ & 1 \\
\hline & Yes & $108(80)$ & $67(24.8)$ & $7.29(2.7,19.68)^{*}$ \\
\hline \multirow{2}{*}{ Antenatal follow-up } & No & $22(16.3)$ & $13(4.8)$ & $2.1(1.35,6.31)$ \\
\hline & Yes & $113(83.7)$ & $257(95.2)$ & 1 \\
\hline \multirow{3}{*}{ Number of antenatal visits } & 1 & $12(10.7)$ & $22(8.3)$ & $2.85(1.02,7.94)^{*}$ \\
\hline & $2-3$ & $51(45.5)$ & $72(27.3)$ & $3.25(0.63,16.72)$ \\
\hline & $\geq 4$ & $49(43.8)$ & $170(64.4)$ & 1 \\
\hline \multirow{2}{*}{ Parity } & $1-4$ & $95(70.4)$ & $235(87)$ & 1 \\
\hline & $\geq 5$ & $40(29.6)$ & $35(13)$ & $1.84(0.44,7.69)$ \\
\hline \multirow{3}{*}{ Gestational age in weeks } & $28-37$ & $44(32.6)$ & $60(22.2)$ & 1 \\
\hline & $37-42$ & $82(60.7)$ & $198(73.3)$ & $1.08(0.36,3.25)$ \\
\hline & $\geq 42$ & $9(6.7)$ & $12(4.4)$ & $0.71(0.07,6.82)$ \\
\hline \multirow{2}{*}{ Previous history of $\mathrm{C} / \mathrm{S}$} & No & $109(80.7)$ & $263(97.4)$ & 1 \\
\hline & Yes & $26(19.3)$ & $7(2.6)$ & $5.51(0.85,35.74)$ \\
\hline \multirow{2}{*}{ Interpregnancy interval after $\mathrm{C} / \mathrm{S}$} & Above 12 months & $10(7.4)$ & $5(1.9)$ & 1 \\
\hline & Less than 12 months & $16(11.9)$ & $2(0.7)$ & $3.42(0.15,79.46)$ \\
\hline \multirow{2}{*}{ Pregnancy complicated by chorioamnionitis } & No & $131(97)$ & $269(99.6)$ & 1 \\
\hline & Yes & $4(3)$ & $1(0.4)$ & $15(0.16,45)$ \\
\hline \multirow{2}{*}{ Place of delivery } & Health center & $8(5.9)$ & $1(0.4)$ & $7.86(0.57,108.2)$ \\
\hline & Hospital & $127(94.1)$ & $269(99.6)$ & 1 \\
\hline \multirow{2}{*}{ Followed by partograph } & No & $118(87.4)$ & $61(22.6)$ & $10(4.53,19.24)$ \\
\hline & Yes & $17(12.6)$ & $209(77.4)$ & 1 \\
\hline \multirow{2}{*}{ Duration of labor } & More than 18 hours & $16(11.9)$ & $1(0.4)$ & $3.45(2.12,20.23)$ \\
\hline & Less than 18 hours & $6(4.4)$ & $197(73)$ & 1 \\
\hline \multirow{2}{*}{ Obstructed labor } & No & $55(40.7)$ & $242(89.6)$ & 1 \\
\hline & Yes & $80(59.3)$ & $28(10.4)$ & $13.33(4.23,42.05)^{*}$ \\
\hline \multirow{2}{*}{ Malpresentation } & No & $117(86.7)$ & $253(93.7)$ & 1 \\
\hline & Yes & $18(13.3)$ & $17(6.3)$ & $1.59(0.25,10.23)$ \\
\hline \multirow{2}{*}{ Labor started spontaneously } & No & $21(15.6)$ & $14(5.2)$ & $3.95(0.93,16.7)$ \\
\hline & Yes & $114(84.4)$ & $256(94.8)$ & 1 \\
\hline \multirow{2}{*}{ Trial of labor after caesarean delivery } & No & $122(90.4)$ & $267(98.9)$ & 1 \\
\hline & Yes & $13(9.6)$ & $3(1.1)$ & $3.5(0.1,117.37)$ \\
\hline \multirow{2}{*}{ Congenital anomalies of baby } & No & $126(93.3)$ & $267(98.9)$ & 1 \\
\hline & Yes & $9(6.7)$ & $3(1.1)$ & $0.57(0.057,5.72)$ \\
\hline \multirow{3}{*}{ Prehemoglobin level } & $\leq 7$ & $15(11.1)$ & $19(7)$ & $2.03(0.61,6.82)$ \\
\hline & $7-11$ & $54(40)$ & $27(10)$ & $1.72(0.45,6.55)$ \\
\hline & $\geq 12$ & $66(48.9)$ & $224(83)$ & 1 \\
\hline \multirow{2}{*}{ Birth weight } & $<4$ & $106(78.5)$ & $252(93.3)$ & 1 \\
\hline & $\geq 4$ & $29(21.5)$ & $18(6.7)$ & $5.68(1.39,23.2)^{*}$ \\
\hline
\end{tabular}

Abbreviations: $\mathrm{C} / \mathrm{S}=$ caesarean section; ${ }^{*}=$ significant variables; $\mathrm{AOR}=$ adjusted odds ratio; $\mathrm{COR}=$ crude odds ratio. 
TABle 5: Maternal and fetal outcomes that develop uterine rupture among mothers who gave birth at public hospitals of Tigrai, North Ethiopia.

\begin{tabular}{|c|c|c|}
\hline Variable & Category & Frequency $(\%)$ \\
\hline \multirow{4}{*}{ What was done } & Total abdominal hysterectomy & $47(34.8)$ \\
\hline & Subtotal hysterectomy & $28(20.74)$ \\
\hline & Uterine repair with bilateral tubal ligation & $26(19.25)$ \\
\hline & Uterine repair without bilateral tubal ligation & $34(25.2)$ \\
\hline \multirow{2}{*}{ Types of uterine rupture } & Complete & $75(55.5)$ \\
\hline & Incomplete & $60(45.5)$ \\
\hline \multirow{3}{*}{ Location of uterine rupture } & Anterior lower uterine segment & $47(34.8)$ \\
\hline & Lateral uterine segment & $35(25.92)$ \\
\hline & Posterior uterine segment & $53(39.25)$ \\
\hline \multirow[t]{2}{*}{ Excessive blood loss } & Yes & $78(57.8)$ \\
\hline & $<7 \mathrm{~g} / \mathrm{dl}$ & $48(11.9)$ \\
\hline \multirow[t]{2}{*}{ Postoperative hemoglobin } & $7-11 \mathrm{~g} / \mathrm{dl}$ & $34(8.4)$ \\
\hline & $>11 \mathrm{~g} / \mathrm{dl}$ & $53(13.1)$ \\
\hline Blood transfusion & Yes & $48(11.9)$ \\
\hline \multirow[t]{2}{*}{ Registered maternal death } & Yes & $13(9.6)$ \\
\hline & Hypovolemic shock & $8(2)$ \\
\hline \multirow[t]{2}{*}{ Immediate cause of maternal death } & Septic shock & $3(0.7)$ \\
\hline & Others* & $2(0.5)$ \\
\hline Registered fetal asphyxia & Yes & $34(25.2)$ \\
\hline Registered fetal death & Yes & $101(74.8)$ \\
\hline
\end{tabular}

${ }^{*}$ Others = pulmonary edema and acute renal failure.

the women, subtotal hysterectomy in 28 (20.74\%), uterine repair with bilateral tubal ligation (BTL) in 26 (19.25\%), and uterine repair without BTL in 34 (25.2\%). Forty-eight $(11.9 \%)$ of the cases had postoperative hemoglobin value (HGB) of $<7 \mathrm{~g}$ per dl; 34 (8.4\%) cases have HGB value of 7$11 \mathrm{~g} / \mathrm{dl}$, and $53(13.1 \%)$ cases have postoperative HGB value of $>11 \mathrm{~g} / \mathrm{dl}$. Among those who had uterine rupture, 48 (11.9\%) of the mothers received blood transfusions.

Thirteen (9.6\%) mothers with uterine rupture died secondary to different immediate causes. The documented immediate causes of maternal deaths were hypovolemic shock [8], septic shock [2], and other causes like pulmonary edema [1] and acute renal failure [1]. Among those who had uterine rupture, $101(74.8 \%)$ of their newborns were stillborn (Table 5).

\section{Discussion}

This unmatched case control study is aimed at identifying the risk factors of uterine rupture and describing maternal and fetal outcomes of uterine rupture. The study identified referral from health facility, number of antenatal care visits, experienced obstructed labor, and birth weight of newborn to be significantly associated with uterine rupture. This study also found maternal death, excessive blood loss, abdominal hysterectomy, and a significant number of stillbirths as untoward outcomes of uterine rupture.

This study identified an association between referral status and uterine rupture. Similar to this study, referred mothers from remote health institutions were associated with uterine rupture in Arbaminch (Southern Ethiopia), Mbarara, Uganda, and Debre Markos, Ethiopia [7, 13, 16]. 80\% of the cases were referred. The reasons for this may be lack of capacity to recognize and manage abnormal pattern of labor at district, primary hospitals and health centers; despite the government's health policy that envisioned decentralizing emergency and comprehensive obstetric services to the community, still many women referred to referral and tertiary hospitals. This may be due to delays in reaching health facilities due to long distances and poor road networks; many mothers end up with uterine rupture.

Studies from Sihul Shire, Ethiopia, Mizan Tepi, Ethiopia, and Mbarara, Uganda $[2,13,17]$ have shown that uterine rupture is highly related with antenatal care attendance, consistent with the findings of this study. The benefit of multiple antenatal visits (recommended four visits) may be contributed through identifying, in advance, maternal risks to rupture, screening for congenital anomalies of fetus, fetal weight, uterine congenital anomalies, malpresentation, and malposition. Therefore, those who have once visited antenatal care may be overlooked in the identification of risk factors contributing to obstructed labor or delaying access to care alternatives (such as caesarian section).

Studies from Sihul Shire (Ethiopia), Mizan Tepi (Ethiopia), and rural Uganda revealed that obstructed labor was a significant risk factor for uterine rupture $[2,5,17]$. This study also showed obstructed labor to be the strongest significant risk factor for uterine rupture. More than half (59.3\%) of the cases had obstructed labor. This is often the case in the sense of unsupervised or undersupervised labor in poorly 
equipped settings, failing detection of prolonged labor by partograph, inadequacy of skilled care providers to detect and give timely, vigilant management for fetal-pelvic disproportion, and overlooked obstructed labor which may lead to rupture due to exhaustion of uterine layers' integrity.

In line with a study conducted in Debre Markos (Ethiopia), France, and Denmark $[4,18,19]$, this finding found that those who had a birth weight of four and above kilograms had high odds of developing uterine rupture. The reason might be failing of detecting fetal macrosomia during antenatal care which contributes to fetal-pelvic disproportion and may lead to prolonged and neglected obstructed labor. Though fetal macrosomia is diagnosed retrospectively after birth, antenatal surveillance is mandatory.

This study revealed that hysterectomy had been performed in more than half of the women who develop uterine rupture. This is consistent with the studies from Debre Markos and Nigeria $[4,15]$ but in discordant with a study from Turkey [20]. The possible explanation could be the differences in health care provider's skills, severity of cases, time for securing hemostasis, the need for fertility and individualized decision-making, and protocols. Among those who had uterine rupture, 48 (11.9\%) of the mothers had received blood transfusion. However, blood transfusions were very common in studies done in Debre Markos (78\%) and Pakistan $(83 \%)[4,21]$. Such variance may relate to the differences in the hemodynamic state of patients and the availability of blood for transfusion. In the current study, 13 (9.6\%) of the mothers with uterine rupture died secondary to different immediate causes, and among those who had uterine rupture, 101 (74.8\%) of the newborns were stillbirths. This finding is consistent with studies done in Yirgalem (Southern Ethiopia), Debre Markos (Ethiopia), Mizan Tepi, Uganda, Nigeria, and Yemen $[4,5,15,17,22,23]$. The possible explanations could be due to the absence of antenatal care followup, distances hindering referral and increasing time to care, contribution of delays from family, and delays in health institutions.

\section{Conclusions}

In conclusion, this study found that referrals from remote health institutions, antenatal care visit once, obstructed labor, and birth weight of newborns were significant determinants of uterine rupture. Maternal death, stillbirth, hysterectomy, and excessive blood loss were adverse outcomes of uterine rupture.

\section{Recommendations}

The early and timely referral of cases should be promoted for rural and remote health institutions. Health care providers should encourage mothers to complete the recommended four visits as these contribute to full risk assessment and screening opportunities for the mom and the fetus. Labor and delivery should be supervised by trained health care provider, enabling timely and early detection of prolonged labor by partograph; early identification of fetal macrosomia during antenatal or early labor by ultrasound or other clinical methods of predicting fetal weight should be recommended. To this end, preventive strategies for obstructed labor require a multidisciplinary approach, as the factors are multifactorial. In the short-term plan, assessing and identifying highrisk mothers are mandatory. In the long term, promoting adequate dietary diversity and improving nutritional status at household level, empowering and educating women to access a good health care, avoiding harmful traditional practices, access to skilled care during pregnancy and childbirth, i.e., risk assessment during antenatal care, and close monitoring and surveillance of fetomaternal conditions during intrapartum care by utilizing partograph appropriately will benefit to reduce obstructed labor and to prevent maternal death secondary to uterine rupture.

\section{Limitations}

The retrospective nature of the study might miss some sociodemographic and socioeconomic variables despite vigorous tracing in the case file, operation room theatre registration, delivery registration books and neonatal cards, and case file. Further prospective studies are needed to identify predictors of uterine rupture and predictors with untoward management outcomes.

\section{Data Availability}

The datasets used and/or analyzed during this study are available from the corresponding author on reasonable request.

\section{Ethical Approval}

Ethical approval was obtained from a research and ethical approval committee of the College of Health Sciences of Adigrat University with a code number AGU/CMHS/084/11. Official cooperation letter was written from Tigray Regional Health Bureau to eastern zone woreda health office then to selected kebelles before data collection was started.

\section{Disclosure}

The funding organization has no role in the design of the study and collection, analysis, and interpretation of data and in writing the manuscript; this was the role of the authors.

\section{Conflicts of Interest}

The authors declare that they have no competing interests.

\section{Authors' Contributions}

$\mathrm{MB}$ was the principal investigator who contributed to the conception and design of the study; collected, entered, analyzed, and interpreted the data; prepared the manuscript; and acted as a corresponding author. DA, NE, WM, SG, BG, MG, FT, HD, HT, HG, and YH contributed to data analysis and interpretation and drafted the manuscript. 


\section{Acknowledgments}

Our appreciation goes to Adigrat University for the financial support. We would like to recognize Tigray Regional Health Bureau for the invaluable support. We would like also to thank the data collectors and administrators of the hospitals for their unreserved cooperation and commitment. Our special gratitude also goes to Professor Pammla Petrucka (University of Saskatchewan Canada, College of Nursing) (through Academics without Borders) for helping us on language and grammar editing and reviewing the whole manuscript.

\section{References}

[1] G. J. S. L. Hofmeyr, L. Say, and A. M. Guilmezoglu, "SYSTEMATIC REVIEW: WHO systematic review of maternal mortality and morbidity: the prevalence of uterine rupture," BJOG, vol. 112, no. 9, pp. 1221-1228, 2005.

[2] S. Gebre and A. Negassi, "Risk factors for uterine rupture in Suhul General Hospital case control study," Electronic Journal of Biology, vol. 13, no. 3, 2017.

[3] S. Saeed, A. Ahmad, and N. Akhtar, "Uterine rupture; four years experience on seventy four cases in secondary care hospital," Professional Medical Journal, vol. 22, no. 8, 2015.

[4] G. Astatikie, M. A. Limenih, and M. Kebede, "Maternal and fetal outcomes of uterine rupture and factors associated with maternal death secondary to uterine rupture," BMC pregnancy and childbirth, vol. 17, no. 1, p. 117, 2017.

[5] I. Kadowa, "Ruptured uterus in rural Uganda: prevalence, predisposing factors and outcomes," Singapore Medical Journal, vol. 51, no. 1, pp. 35-38, 2010.

[6] R. Strand, P. Tumba, J. Niekowal, and S. Bergström, "Audit of cases with uterine rupture: a process indicator of quality of obstetric care in Angola," African Journal of Reproductive Health, vol. 14, no. 2, pp. 55-62, 2010.

[7] S. A. Alyu and T. B. Lema, "Prevalence and associated factors of uterine rupture during labour among women who delivered in Debremarkos hospital," Internal Medicine, vol. 6, no. 4, p. 222, 2016.

[8] T. L. Dadi and T. E. Yarinbab, "Estimates of uterine rupture bad outcomes using propensity score and determinants of uterine rupture in Mizan-Tepi University teaching hospital: case control study," Journal of pregnancy, vol. 2017, 9 pages, 2017.

[9] Y. Berhan and A. Berhan, "Causes of maternal mortality in Ethiopia: a significant decline in abortion related death," Ethiopian journal of health sciences, vol. 24, pp. 15-28, 2014.

[10] Z. A. Al-Jufairi, A. K. Sandhu, and K. A. Al-Durazi, "Risk factors of uterine rupture," Saudi medical journal, vol. 22, no. 8, pp. 702-704, 2001.

[11] M. Kaczmarczyk, P. Sparén, P. Terry, and S. Cnattingius, "Risk factors for uterine rupture and neonatal consequences of uterine rupture: a population-based study of successive pregnancies in Sweden," BJOG: An International Journal of Obstetrics \& Gynaecology, vol. 114, no. 10, pp. 1208-1214, 2007.

[12] I. Al-Zirqi, A. K. Daltveit, L. Forsén, B. Stray-Pedersen, and S. Vangen, "Risk factors for complete uterine rupture," Obstetric Anesthesia Digest, vol. 37, no. 4, pp. 173-174, 2017.

[13] P. K. Mukasa, J. Kabakyenga, J. K. Senkungu, J. Ngonzi, M. Kyalimpa, and V. J. Roosmalen, "Uterine rupture in a teaching hospital in Mbarara, western Uganda, unmatched case- control study," Reproductive health, vol. 10, no. 1, p. 29, 2013.

[14] B. Lindtjørn, D. Mitiku, Z. Zidda, and Y. Yaya, "Reducing maternal deaths in Ethiopia: results of an intervention programme in southwest Ethiopia," PLoS One, S. Gebhardt, Ed., vol. 12, no. 1, pp. e0169304-e0169308, 2017.

[15] A. M. Abasiattai, A. J. Umoiyoho, N. M. Utuk, E. C. InyangEtoh, and O. P. Asuquo, "Emergency peripartum hysterectomy in a tertiary hospital in southern Nigeria," The Pan African Medical Journal, vol. 15, no. 60, pp. 1-15, 2013.

[16] G. Girmay, T. Gultie, G. Gebremichael, B. Afework, and G. Temesgen, "Determinants of uterine rupture among mothers who gave birth in Jinka and Arba Minch general hospitals, institution-based case-control study, southern Ethiopia, Ethiopia, 2019," Women's Health, vol. 16, pp. 174550652096172-174550652096177, 2020.

[17] T. L. Dadi and T. E. Yarinbab, "Estimates of uterine rupture bad outcomes using propensity score and determinants of uterine rupture in Mizan-Tepi University Teaching Hospital: case control study," Journal of pregnancy, vol. 6, no. 2, 2017.

[18] A. Pinton, E. Boudier, A. Joal et al., "Risk factors and clinical presentation of uterine rupture in the unscarred uterus: a case control study," Journal of Pregnancy and Child Health, vol. 3, no. 5 , p. 2, 2016.

[19] D. L. A. Thisted, L. H. Mortensen, and L. Krebs, "Uterine rupture without previous caesarean delivery: a population-based cohort study," European Journal of Obstetrics \& Gynecology and Reproductive Biology, vol. 195, no. 4, pp. 151-155, 2015.

[20] A. Turgut, A. Ozler, M. S. Evsen et al., "Uterine rupture revisited: predisposing factors, clinical features, management and outcomes from a tertiary care center in Turkey," Pakistan Journal of Medical Sciences, vol. 29, no. 3, pp. 1-7, 2013.

[21] Q. QAZI, Z. AKHTAR, K. KHAN, and A. H. KHAN, "Woman health; uterus rupture, its complications and management in Teaching Hospital bannu, pakistan," Pakistan Moedica - a Journal of Clinical Medicine, vol. 7, no. 1, pp. 49-53, 2012.

[22] I. S. J. Dhaifalah and H. Fingerova, "Uterine rupture during pregnancy and delivery among women attending the AlTthawra Hospital in Sana'a City Yemen Republic," Biomedical Papers, vol. 150, no. 2, pp. 279-283, 2006.

[23] A. Gebretsadik, H. Hagos, and K. Tefera, "Outcome of uterine rupture and associated factors in Yirgalem general and teaching hospital, southern Ethiopia: a cross-sectional study," BMC pregnancy and childbirth, vol. 20, no. 1, pp. 256-257, 2020. 